\title{
Measurement of Organizational Citizenship Behaviour; Reliability and Validity in Sri Lankan Context
}

\author{
M.P.N. Janadari ${ }^{1 *}$, Subramaniam Sri Ramalu ${ }^{2}$ and Chuah Chin $\mathrm{Wei}^{3}$ \\ ${ }^{1}$ Department of Human Resource Management, University of Kelaniya, Sri Lanka, \\ ${ }^{2}$ Othman Yeop Abdullah Graduate School of Business, University Utara Malaysia, \\ ${ }^{3}$ Colleges of Business, University Utara Malaysia \\ 1njanadari@yahoo.com, ${ }^{2}$ subra@uum.edu.my, ${ }^{3}$ francischuah@uum.edu.my \\ * https://orcid.org/0000-0001-7704-048X
}

\begin{abstract}
This paper investigates the goodness of the measure of organizational citizenship behaviour in terms of reliability and validity. Organizational Citizenship Behaviour considers as the extra role or voluntary behaviour not directly or explicitly recognized by the formal reward system, and that in the aggregate it promotes the effective functioning of the organization. However, more research studies on OCB focus on western context while similar effort in Sri Lankan context rather scant. Data were gathered through the survey by distributing structured questionnaire from public sector organizations. As per the discussion basically, two main criteria called reliability and validity have to be achieved to confirm the goodness of the measure. Internal reliability and composite reliability scales were commonly employed to asses construct reliability of the intended constructs. However, convergent validity achieved through Average Variance Extracted (AVE) and factor loadings. Discriminant validity can be evaluated by assessing the cross loadings among constructs, Fornel-Larcker criterion, and Heterotrait- Monotrait Ratio of correlation (HTMT). According to the derived outcomes implications regarding the goodness of measure were discussed and revisions of measurement in Sri Lankan context were presented.
\end{abstract}

Keywords: Organizational Citizenship Behaviour, Measurement, Composite Reliability, Convergent Validity, Discriminant Validity

\section{Introduction}

Much of the scholarly concentration in OCBs stems from the extensive belief that OCBs improve the efficiency and effectiveness of organizations (Organ, Podsakoff \& Mackenzie, 2006). Organizational Citizenship Behaviour defines as individual behaviour that is discretionary, not directly or explicitly recognized by the formal reward system, and that in the aggregate promotes the effective functioning of the organization (Organ, 1988). In the first part of the original definition, OCB treats as the notion of discretion, which means that engagement in OCB is completely voluntary (Organ et al., 2006) or not an enforceable by supervisors or superiors, it is rather a matter of persons choice, such that its omission is not generally understood as punishable (Organ ,1998). Further, it highlights that task performance and OCB are separated and OCB is not explicitly recognized by the formal reward system (Organ, 1997). 
OCBs include both behaviours that are directed toward specific persons (e.g. interpersonal helping), as well as more impersonal forms of conscientiousness and workplace involvement that contribute to organizational effectiveness (e.g. sportsmanship, organizational loyalty, organizational compliance, individual initiative (Organ et al., 2006)). These extra-role behaviours are likely to facilitate social and psychological contexts that support task performance in the organization (Organ, 1997). As a whole, OCB could contribute to enhancing employees and managerial productivity, attract retention, improve coordination, reduce friction, viability of performance and increase adaptation to environmental changes (Podsakoff, MacKenzie, Paine, $\&$ Bachrach, 2000).

\section{Objective of the Study}

To find out the internal reliability and the validity of the concept of organizational citizenship behaviour.

\section{Literature Review}

Katz and Kahn's (1966) "The social psychology of organizations" pave the path to thinking about OCB within the context of open system as a model of organization theory. Katz (1964) explained that behaviours which are helpful, innovative and cooperative are essential for organizational operations. The notion of OCB from its conception has been considered as multidimensional. Podasakoff and colleagues (2000) noted that almost 30 potentially different forms of citizenship behaviours had been suggested since the origination. The emergence of this large number of constructs highlighted the widespread interest in and relevance of organizational citizenship research. Dennis Organ is generally considered as the father of the OCB, and he is looking for the good soldiers who will work determinedly and obediently to accomplish organizational goals and objectives. Organ deconstructed the dimensions of OCB based on the Katz and Khan's work. This deconstruction extended five-factor model which was composed with Altruism, Courtesy, Conscientiousness, Civic virtue and Sportsmanship.

Altruism refers to discretionary behaviours that help another person with task related problems. Conscientiousness characterized by the behaviours that go well beyond the in -role job requirements (Law, Wong \& Chen, 2005). Organ (1988) linked Conscientiousness with "should" type behaviour, indeed it is more on the notion of code or level of resolve as to how one should behave. Civic Virtue has characterized the behaviours that employee's deep concerns and active interest in the life and the culture of the organization (Law et al., 2005). Courtesy has been defined as voluntary behaviours that aim at preventing work related conflicts with others (Law et al., 2005). Specifically, it attempts to mitigate interpersonal problems from occurring by giving advance notice and try to prevent from encountering unpleasant surprises. Finally, Sportsmanship has been defined as a person's desire not to complain unnecessarily and being positive and tolerant when experiencing the inevitable inconveniences. On some occasions they are willing to sacrifice their own personal interest for the sake of group interest. These behaviours reflect an employee recognition of being a part of the organization (Podsakoff et al., 2000). 


\section{Measurements}

The first decision to be made in operationalizing a construct is to decide on what is the intended level of measurement. Different measures have been designed and developed by researchers. The first scale was designed by Bateman and Organ (1983) which was used to measure Organizational citizenship behaviour. According to them, "OCB include any of those gestures, that lubricate the social machinery of the organization but that do not directly in here in the usual notion of task performance." This scale was a 30 item OCB scale that comprises of variety of types of OCB like cooperation, altruism, compliance, punctuality, housecleaning, protecting company property, conscientiously following company rules and dependability. A 16item scale was developed by Smith, Organ and Near (1983). According to them, "Citizenship Behaviours comprise a dimension if individual and group functioning. The latter was regarded as a function of the formal organization and the logic of facts." This scale comprises of two factors namely Altruism and Generalized Compliance. The third scale was given by Podsakoff, Mackenzie, Moorman, and fetter (1990), they identified the following five factors of Organizational Citizenship Behaviour: Altruism,

Conscientiousness, Sportsmanship, Courtesy and Civic virtue. Fourth scale was developed by Williams and Anderson (1991) that defined that the Organizational citizenship Behaviour has two broad categories as OCBO - behaviours that benefit the organization in general and OCBI - behaviours that immediately benefit specific individuals and indirectly through this means contribute to the organization. This is a fourteen item scale with seven items on OCBO and seven items on OCBI. Another scale of OCB designed by Moorman and Blakely (1995) when they came out with another scale on OCB. It was a 19 item scale that comprises of items on Interpersonal Helping, Individual initiative, Personal industry and Loyal Boosterism. After so many research development in the western culture it was found that most of the researches, findings and measures were influenced by the western culture hence this attracted few researchers to design something that shall be applicable in Asian countries and may be in different cultures.

\section{Assessment of Construct Reliability}

PLS-SEM or partial least squares path modeling is a variance-based structural equation that has become very popular in recent years (Henseler, Hubona \& Ray, 2016). In PLS analysis, the first step is to assess the measurement model or the outer model. The two main criteria used in PLS analysis to assess the measurement model or what is alternatively called the outer model include validity and reliability (Ramayah, Lee \& In, 2011). The individual item reliability, construct internal consistency and construct validity are considered in assessing the outer model in PLS. Reliability is a quality criterion of a construct; it requires a high level of correlation among the indicators of a particular construct (Kline, 2011). The internal reliability of a construct is said to be achieved when the Cronbach's Alpha value is 0.7 or higher (Nunnally \& Beinstein, 1994). However, Composite reliability more 
concern on individual reliability referring to different outer loadings of the indicator variables (Hair, Hult, Ringle, \& Sarstedt, 2017). The cut off for composite reliability is the same as any measure of reliability and score between 0.6 and 0.7 is a good indicator of construct reliability (Hensele \&, Sarstedt, 2013).

\section{Assessment of Validity}

Validity concerns the soundness of the accuracy of a measure or the extent to which a score truthfully represents a concept (Zikmand, Babin, Carr \&Griffin, 2013). In order to achieve validity analysis, two kinds of validity tests were performed in PLS on the measurement scales namely: convergent validity and discriminant validity (Sekaran \& Bougie, 2010). Convergent validity is the extent to which a measure correlates positively with an alternative measure of the same construct. In examining the convergent validity of a measure in PLS, the average variance extracted (AVE) and item loadings are assessed (Hair et al., 2013). Discriminant validity is concerned about the uniqueness of a construct, whether the phenomenon captured by a construct is unique and not represented by the other constructs in the model (Hair, Ringle, \& Sarstedt, 2013). Discriminant validity can be evaluated by assessing the cross loadings among constructs, by using Fornel-Larcker criterion and Heterotrait-Monotrait Ratio of correlation (HTMT).

\section{Methodology}

The study involves a testing of measurements and it is quantitative, deductive in nature. Employed survey method and cross sectional study in type with minimum researcher interference. Unit of analysis is the individual employees belonging to the front line worker employees of the public sector organizations in Sri Lanka. The employees' OCB is measured by using 24 item OCB, which was developed by the Podsakoff and colleagues (2000) based on the Organ's five-dimensional taxonomy. The five-point Likert scale designed from 1 (strongly disagree) to 5 (strongly agree). The purpose of the study is to test the reliability and validity of measure of organizational citizenship behaviour in Sri Lankan context. A sample of 296 employees from the public sector organizations was drawn with disproportionate stratified random sampling method. Questionnaires were distributed to the respondents. This study recorded a nearly $67 \%$ of response rate. It seems that the external validity of the finding of this study can be held high with this higher response rate.

\section{Discussion}

The construct reliability and validity test were conducted to evaluate the measurement of the construct of OCB. Composite reliability as a greater measurement instrument will explain the internal consistency of the manifest variables concerning items differently. The table 1.4 illustrated that all loadings are above the cutoff values and composite reliability of every construct was well above ranging from 0.788 to 0.809 as per the suggested 0.70 threshold. Further, Convergent validity examined concerning the item reliability or the factor loadings and Average Variance Extraction of the constructs. AVE value equal or higher than 0.50 indicates that on the average, the 
construct explained more than half of the variance of its indicators. As such, the rule of thumb is that an AVE value greater or equal to 0.50 is acceptable (Hair et al., 2013; Barclay, Higgins, \& Thompson, 1995). However, out of the initial 24 items eight indicators omission from the construct of OCB as OCBA1 (0.608), OCBA2 (0.577) ,OCBS4
(0.645) ,OCBS5 (0.616) ,OCBCON1 (0.649), OCBCON5 (0.618), OCBCUR4 (0.637), OCBCUR (0.636) to increase the composite reliability and the AVE. In the present study, the values of AVE of all revised variables exceeded the threshold which indicates the good construct validity of measures.

\section{Table 1: Quality Criteria of the Construct OCB}

\begin{tabular}{|c|c|c|c|c|c|c|}
\hline 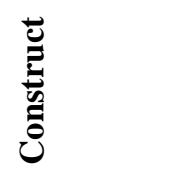 & อ & $\stackrel{\Xi}{\Xi}$ & : & 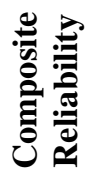 & $\frac{\pi}{2}$ & 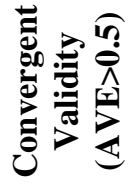 \\
\hline \multirow{16}{*}{$\begin{array}{l}\text { Organizati } \\
\text {-onal } \\
\text { Citizenship } \\
\text { Behaviour }\end{array}$} & \multirow[t]{3}{*}{ Altruism } & OCBA3 & 0.783 & \multirow[t]{3}{*}{0.797} & \multirow[t]{3}{*}{0.567} & \multirow[t]{3}{*}{ Yes } \\
\hline & & OCBA4 & 0.722 & & & \\
\hline & & OCBA5 & 0.754 & & & \\
\hline & \multirow[t]{3}{*}{ Conscientiousness } & OCBCON2 & 0.708 & \multirow[t]{3}{*}{0.788} & \multirow[t]{3}{*}{0.554} & \multirow[t]{3}{*}{ Yes } \\
\hline & & OCBCON3 & 0.758 & & & \\
\hline & & OCBCON4 & 0.765 & & & \\
\hline & \multirow{3}{*}{$\begin{array}{l}\text { Sportsman } \\
\text { ship }\end{array}$} & OCBS1 & 0.762 & \multirow[t]{3}{*}{0.809} & \multirow[t]{3}{*}{0.586} & \multirow[t]{3}{*}{ Yes } \\
\hline & & OCBS2 & 0.824 & & & \\
\hline & & OCBS3 & 0.706 & & & \\
\hline & \multirow[t]{3}{*}{ Courtesy } & OCBCUR1 & 0.747 & \multirow[t]{3}{*}{0.798} & \multirow[t]{3}{*}{0.569} & \multirow[t]{3}{*}{ Yes } \\
\hline & & OCBCUR2 & 0.774 & & & \\
\hline & & OCBCUR3 & 0.741 & & & \\
\hline & \multirow[t]{4}{*}{ Civic virtue } & OCBCV1 & 0.697 & \multirow[t]{4}{*}{0.809} & \multirow[t]{4}{*}{0.515} & \multirow[t]{4}{*}{ Yes } \\
\hline & & OCBCV2 & 0.718 & & & \\
\hline & & OCBCV3 & 0.774 & & & \\
\hline & & OCBCV4 & 0.678 & & & \\
\hline
\end{tabular}

In order to confirm construct validity of the outer model, the discriminant validity is indispensable. Discriminant validity explains about the extent to which a construct is truly distinct from other constructs by empirical stands. At first, in order to achieve discriminant validity, the loadings of the construct must be high on itself and low on other constructs (Vinzi, Henseler, Chin \& Wang, 2010). The following table (Table 02) clearly explain that all the loadings under the construct itself are well above than the cross loadings. 
Table 2: Loading and Cross Loading of Constructs to Assess Discriminant Validity

\begin{tabular}{lrrrrr}
\hline & OCBA & OCBCON & OCBS & OCBCUR & OCBCV \\
\hline OCBA3 & $\mathbf{0 . 7 8 3}$ & 0.349 & 0.365 & 0.284 & 0.453 \\
OCBA4 & $\mathbf{0 . 7 2 2}$ & 0.361 & 0.196 & 0.275 & 0.354 \\
OCBA5 & $\mathbf{0 . 7 5 4}$ & 0.367 & 0.300 & 0.196 & 0.395 \\
OCBCON2 & 0.369 & $\mathbf{0 . 7 0 8}$ & 0.151 & 0.257 & 0.373 \\
OCBCON3 & 0.328 & $\mathbf{0 . 7 5 8}$ & 0.182 & 0.152 & 0.441 \\
OCBCON4 & 0.365 & $\mathbf{0 . 7 6 5}$ & 0.258 & 0.272 & 0.369 \\
OCBS1 & 0.281 & 0.166 & $\mathbf{0 . 7 6 2}$ & 0.270 & 0.268 \\
OCBS2 & 0.291 & 0.230 & $\mathbf{0 . 8 2 4}$ & 0.312 & 0.215 \\
OCBS3 & 0.315 & 0.215 & $\mathbf{0 . 7 0 6}$ & 0.311 & 0.187 \\
OCBCUR1 & 0.208 & 0.222 & 0.341 & $\mathbf{0 . 7 4 7}$ & 0.187 \\
OCBCUR2 & 0.267 & 0.220 & 0.309 & $\mathbf{0 . 7 7 4}$ & 0.331 \\
OCBCUR3 & 0.280 & 0.252 & 0.227 & $\mathbf{0 . 7 4 1}$ & 0.155 \\
OCBCV1 & 0.370 & 0.304 & 0.243 & 0.237 & $\mathbf{0 . 6 9 7}$ \\
OCBCV2 & 0.380 & 0.396 & 0.234 & 0.227 & $\mathbf{0 . 7 1 8}$ \\
OCBCV3 & 0.337 & 0.430 & 0.174 & 0.170 & $\mathbf{0 . 7 7 4}$ \\
OCBCV4 & 0.443 & 0.384 & 0.185 & 0.240 & $\mathbf{0 . 6 7 8}$ \\
\hline
\end{tabular}

Apart from that, discriminant validity of a construct can be assessed by comparing the square root of the AVE values with latent variable correlations (Fornell \& Larcker, 1981). The square roots of AVE coefficients are presented in the correlation matrix along the diagonal. The squared root of each constructs' AVE should be greater than its highest correlation with any other construct to evidence discriminant validity (Hair et al., 2013).

Table 3: Fornell and Larcker Criterion for Discriminant Validity

\begin{tabular}{llllll}
\hline & Altruism & Civic Virtue & Conscientiousness & Courtesy & Sportsmanship \\
\hline Altruism & $\mathbf{0 . 7 5 3}$ & & & & \\
Civic Virtue & 0.534 & $\mathbf{0 . 7 1 8}$ & & & \\
Conscientiousness & 0.476 & 0.529 & $\mathbf{0 . 7 4 5}$ & & \\
Courtesy & 0.334 & 0.305 & 0.305 & $\mathbf{0 . 7 5 4}$ & \\
Sportsmanship & 0.386 & 0.292 & 0.267 & 0.389 & $\mathbf{0 . 7 6 5}$ \\
\hline
\end{tabular}

Finally, a new criterion HTMT was introduced by the recent research done by the Henseler, Ringle and Sarstedt (2015) based on their Monte Carlo Simulation. According to Henseler, Ringle and Sarstedt (2016) in order to achieve discriminant validity, the HTMT score should be below 0.85 (Henseler et al., 2015) and Table 4 depicts that study construct already fulfilled the expected threshold values. 
Table 4: Heterotrait Monotrait (HTMT) Criterion for Discriminant Validity

\begin{tabular}{lrrrr}
\hline & Altruism & Civic Virtue & Conscientiousness & Courtesy \\
\hline Altruism & & & & \\
Civic Virtue & 0.816 & & & \\
Conscientiousness & 0.784 & 0.827 & & \\
Courtesy & 0.536 & 0.455 & 0.501 & \\
Sportsmanship & 0.606 & 0.44 & 0.427 & 0.612 \\
\hline
\end{tabular}

\section{Findings and Conclusion}

This study is intended to test the goodness of measure for organizational citizenship behaviour construct in the Sri Lankan context. The purpose of testing the measurement of organizational citizenship behaviour construct will add to the contextual validity in a different context. The outcome of the reliability test shows that measurement has a better internal consistency in measuring the construct and it is stabilized. Further, in line with construct validity; convergent and discriminant validity added more confirmation on the accuracy of the measurement. Convergent validity tested the degree to which indicators of a particular construct converge or share a high proportion of variance in common (Hair et al., 2010) while Discriminant validity is referred to the uniqueness of a construct, whether the phenomenon captured by a construct is unique and not represented by the other constructs in the model. The original item structure has 24 items to measure and that was not totally consistent with the pre-test model of the present study given the fact that several items had to be dropped due to low loading.Therefore, the finding of this study exhibits the differences on the dimensionality of OCB in a different context from where it was mostly tested. Any way the revised model results clearly shows that all manifest variables measure the same construct achieving convergent validity and exhibits the discriminant validity and are distinct from one another. It can be an impetus for increase studies in the Sri Lankan context given the fact that more research required for its conceptual clarity and validity.

\section{References}

Barclay, D. W., Higgins, C. A., \& Thompson, R. (1995). The partial least squares approach to causal modelling: personal computer adoption and use as an illustration. Technology Studies, 2, 285-309.

Fornell, Claes, \& Larcker, David F. (1981). Evaluating structural equation models with unobservable variables and measurement error. Journal of marketing research, 39-50.

Hair, J. F., Hult, G. T.M., Ringle, C.M., \& Sarstedt, M. (2017). A primer on partial least squares structural equation modeling (PLS-SEM) (2 ed.). Thousand Oaks, CA: Sage. 
Hair, J. F., Jr., Black, W. C., Babin, B. J., \& Andersen, R. E., (2010). Multivariate data analysis (7th ed.). Upper Saddle River, NJ: Pearson Prentice Hall. 280

Hair, J. F., Ringle, C. M., \& Sarstedt, M. (2013). Partial least squares structural equation modelling: Rigorous applications, better results and higher acceptance. Long Range Planning, 46, 1-12.

Henseler, J. \& Sarstedt, M. (2013), “Goodness-of-fit indices for partial least squares path modelling”, Computational Statistics, Vol. 28 No. 2, pp. 565-580.

Henseler, J., Ringle, C. M., \& Sarstedt, M. (2016). Testing measurement invariance of composites using partial least squares. International Marketing Review

Henseler, J., Ringle, C.M., \& Sarstedt, M. (2015). A new criterion for assessing discriminant validity in variance-based structural equation modelling. Journal of the Academy of Marketing Science, 43(1), 115-135.

Henseler, J.,Hubona G.,Ray P.A.( 2016)Using PLS path modelling in new technology research: updated guidelines Industrial Management \& Data Systems, Vol. 116 Iss 1 pp. 2 - 20

Katz, D., \& Kahn, R. L. (1966). The social psychology of organizations. New York: Wiley

Kline, R. B. (1998). Principles and Practice of Structural Equation Modelling. New York: The Guilford Press

Law, S. K., Wong, C., \& Chen, X. Z. (2005). The construct of organizational citizenship behaviour: Should we analyse after we have conceptualized? In D. L. Turnipseed (Ed.), Handbook of organizational citizenship behaviour (pp. 47-65). New York: Nova Science Katz, D. (1964). The motivational basis of organizational behaviour. Behavioural Science, 9(2), 131-146.

Nunnally, J.C., \& Bernstein, I.H. (1994). Psychometric theory. McGraw, New York.

Organ, D. W. (1988). Organizational citizenship behaviour: The good soldier syndrome. Lexington, MA: Lexington Books.

Organ, D. W. (1997). Organizational Citizenship Behavior: It's Construct Clean-Up Time. Human Performance, 10(2), 85-97.

Organ, D. W., Podsakoff, P. M., \& Mackenzie, S. B. (2006). Organization citizenship behavior: Its nature, antecedents, and consequences. Thousand Oaks. California: Sage Publication.

Podsakoff, P. M., MacKenzie, S. B., Paine, J. B., \& Bachrach, D. G. (2000). Organizational Citizenship Behaviors: A critical review of the theoretical and empirical literature and suggestions for future research. Journal of Management, 26(3), 513-563. http://doi.org/10.1177/014920630002600307

Ramayah, T., Lee, J. W. C. \& In, J. B. C. (2011). Network collaboration and performance in the tourism sector. Service Business, 5, 411-428. 
Ringle, C.M., Wende, \& Will, A. (2010c), "Finite mixture partial least squares analysis: methodology and numerical examples", in Esposito Vinzi, V., Chin, W.W., Henseler, J. and Wang, H. (Eds), Handbook of Partial Least Squares: Concepts, Methods and Applications, Springer, Berlin, pp. 195-218.

Vinzi, V.E.,Chinw.W.,Henseler,J.,\&Wang,H.(2010).The Hand book of Partial Least Square: Concepts, Methods and Applications: Springer Berlin Heidelberg

Zikmund, W.G.,Babin,B.J., Carr,J.C.,Griffin,M.,(2013). Business Research Methods $\left(9^{\text {th }}\right.$ Edition).Nelson Education Ltd. Canada 